\title{
Benefits of physical activity in neurotrophic factors
}

\author{
Marco BATISTA, Samuel Alexandre HONÓRIO *, João SERRANO, João PETRICA, Jorge SANTOS \\ Sport, Health and Exercise Research Unit (SHERU), Instituto Politécnico de Castelo Branco, Castelo Branco, \\ Portugal
}

*Corresponding author: Samuel Alexandre Honório, Rua Prof. Dr Faria de Vasconcelos, 6000-266 Castelo Branco, Portugal. E-mail: samuelhonorio@ipcb.pt

\begin{abstract}
A B S T R A C T
This work is a review with a main objective: to develop knowledge about physical activity in neurotrophic factors. We have outlined three objectives within the affective, psychomotor and cognitive domains. These are respectively: the value of the practice of physical activity (PA) and to explain the relationship between the practice of PA and neurotrophic factors. For the accomplishment of this work, informative documents were searched through Google Scholar, Online Library of Knowledge (B-ON), PubMed and Scopus DataBase. The study addresses the concept of PA, the benefits and factors associated with adherence, persistence and abandonment of regular physical activity and in a second phase the concept of neurotrophic factors and the relationship that exists between the practice of PA and neurotrophic factors. Physical exercise increases the expression of a protein called brain-derived neurotrophic factor (BDNF). A connection has been established between physical exercise, the levels of this neurotrophin and its beneficial effects on the brains of animals and humans. It has recently been shown that exercises sessions are capable of increasing serum and plasma BDNF concentration in addition to an increase in BDNF expression in skeletal muscle. In this review will be approached the effect of physical exercise on the expression of BDNF in the brain. Recent studies have shown that there is a potential benefit in increasing BDNF expression and release by brain and some peripheral tissues, induced by exercise, resulting in an improvement in brain function.
\end{abstract}

(Cite this article as: Batista M, Honório SA, Serrano J, Petrica J, Santos J. Benefits of physical activity in neurotrophic factors. Minerva Ortop Traumatol 2018;69:84-9. DOI: 10.23736/S0394-3410.18.03883-3)

KEY WORDS: Exercise - Brain-derived neurotrophic factor - Review.

$\mathrm{P}$ hysical activity is recognized today by the execution of movements that leads to gains in health, control and prevention of diseases, physical and emotional well-being and can also function as an antistress tool. Vasconcelos et al. ${ }^{1}$ states that PA is a behavior that occurs in a variety of forms and contexts, and is therefore considered as a biocultural process, that is, energy is spent in active behaviors that within a cultural context. It follows that the approach of PA should not be carried out from an exclusively biological or cultural point of view. It requires the understanding of the biocultural determinants of an active or inactive lifestyle. The execution of movements of the body produced by the muscles leads to the expenditure of energy, that is, the PA. Mendes et al. ${ }^{2}$ considers that physical exercise is a subtype of PA, which is planned, organized, repeatable and whose objective is to improve or maintain physical fitness and health. According to the World Health Organization $^{3}$ PA is any body movement produced by skeletal muscles that requires energy expenditure including activities performed while working, playing, performing household chores, traveling, and practicing recreational activities. The organization further says that the term "physical activity" should not be confused with "physical exercise", which is a subcategory of planned, structured, repetitive PA intended to improve or maintain one or more components of physical fit- 
ness. Bounds et al. ${ }^{4}$ states that physical activity is defined as the body movement produced by the skeletal muscles, which requires an energy expenditure and produces healthy benefits. Physical exercise is defined as a planned, structured, and repetitive bodily movement made to enhance or maintain one or more components of physical fitness. Physical inactivity results in a lower level of activity than is necessary to maintain good health.

\section{Benefits of physical activity}

From very early is evidenced the importance to the practice of physical exercise. In the early days there arose the need to have physical fitness to cross obstacles that arose and to demonstrate superiority and dexterity, and the more capable ones obtained greater gains. Moreira et al. ${ }^{5}$ refers that a few thousand years ago the survival of man, as for any other animal, was strongly dependent on physical fitness. Not only the heart, but also the lungs, the kidneys and the brain, also the skeletal muscle activity conditioned the survival of the human species. Physical exercise is extremely important in the reality in which we live in. It presents preventive and therapeutic benefits (reduction of incidence of cardiovascular diseases) and minimizes risk factors (hypertension, obesity). ${ }^{6}$ Flores et al. ${ }^{7}$ refers that regular practice of physical exercises is accompanied by benefits that manifest in every aspect of the body. It assists in improving strength and muscle tonicity and flexibility, strengthening of bones and joints, all these benefits help in the prevention and control of diseases, and are important for reducing the mortality associated with them. Lazzoli et $a l .{ }^{8}$ mentioned that in children and adolescents, a higher level of PA has contributions to the improvement of the lipid and metabolic profile and reduces the prevalence of obesity. They also point out that a physically active child is more likely to become an active adult. As a consequence, from the standpoint of public health and preventive medicine, promoting physical activity in childhood and adolescence means laying a solid foundation for reducing the prevalence of sedentary lifestyle in adulthood, thereby contributing to better quality of life. Lazzoli et al. ${ }^{8}$ also reported that an active lifestyle in adults is associated with a reduction in the incidence of several chronic degenerative diseases as well as a reduction in cardiovascular and general mortality.

According to Matsudo et al. ${ }^{9}$ in the case of the elderly a suitable muscular training program provides multiple benefits both anthropometric, as neuromuscular, metabolic and psychological. They also mention that it serves as prevention and treatment of age-related diseases such as hypertension and osteoporosis and improves the quality of life and independence of individuals. There are studies that demonstrate the benefits of PA regarding the incidence of colon and reproductive cancer in women. Matsudo et al. ${ }^{9}$ also report an increase of up to 2.5 years in life expectancy due to participation in a regular physical exercise program. Thus, probably in addition to offering a better quality of life, physical activity provides more years of life". At present, it is known that the benefits of PA are not only physical and directly related to health, they are verifiable in several dimensions. Studies have shown that regular practice of PA is linked to greater satisfaction with life, increased quality of life, and greater personal satisfaction. Silva et al. ${ }^{10}$ state that physical exercise is a trait of leisure and helps to restore health of the harmful effects that the stressful routine of work and study brings. The exercise, after the initial period, is an activity that is usually pleasant and that brings numerous benefits to the practitioner, ranging from the improvement of the lipid profile to the improvement of self-esteem. Silva et al. ${ }^{10}$ conclude that, regardless of the gender, age and occupation of the individuals, it is evident that the PF reveals improvements in the quality of life in all aspects.

\section{Factors associated with adherence, persistence and abandon of regular physical activity}

As mentioned previously in this work, the practice of regular PA promotes several benefits. However, these benefits are reversible if this practice is not maintained. Costa et al. ${ }^{11}$ state that “... keeping physically active individuals on a regular basis has become one of the major public health challenges." In this sense, it is important to understand the factors that determine whether in- 
dividuals adhere, remain or abandon the practice of regular PA, factors that allow, in a direct way, the maintenance, increment or regression of the benefits gained. According to Silva et al. ${ }^{11}$ these factors can be grouped in the individual category or in the environmental category. Within the individual category this author includes factors such as: motivation, self-efficacy, historical of PA, stages of change, body weight, risk factors, diet and stress. The environmental category includes factors such as: social support, time, access to the practice, exercise characteristics and damages caused by exercise. Silva et al. ${ }^{11}$ group the factors by categories considering four: demographic variables (age, sex, socioeconomic level, educational level); cognitive variables (perception of barriers, intention to exercise, mood disorders, health perception, self-efficacy, perceived exertion); environmental variables (climate, ease of access and appropriate locations); and social support (family and friends). Before the practice of physical exercise four possibilities of behavior can be identified. ${ }^{12}$ One possibility relates to adherence to PA where the belief in the health benefits is predominant and motivation is more likely to be related to well-being. The second possibility of behavior is related to persistence, maintenance of PA that is associated with more self-motivated people, people who set their own goals, who have family support and their adherence is more related to feelings of well-being and pleasure, not realizing inconveniences in physical exercise. The third possibility of behavior is related to the withdrawal, abandonment of the PA being associated with lack of time, inconvenience, lack of motivation, situational factors, being a more marked behavior in people who have a history of inactivity or low physical and motor capacities. Finally, the fourth possibility of behavior is related to the resumption of PA and is related to a better capacity of time management, with a sense of control, self-confidence, with more flexible goals and positive thinking. Focusing on the quit factors Sautos et al. ${ }^{12}$ list lack of time, energy and motivation as the excuses that people present for not exercising. However, the study of these reasons allowed us to realize that the issue of lack of time is not to prioritize PA or PA programs to be uninteresting; the issue of lack of energy mainly concerns mental fatigue and should be a motive for practice from the knowledge of the benefits; the question of lack of motivation is a factor that results from the sum of fatigue and dedication of time to other activities. Thus, to maintain the benefits of PA, it is necessary to stimulate the maintenance of regular practice of PA. ${ }^{11}$ According to the same author PA programs that focuses on the factors that determine the adherence to PA, namely individual and environmental determinants, appears to be effective. Sautos et al. ${ }^{12}$ add a solution for a physically active population would go through education for the practice of PA from childhood, encourage practice during adolescence, facilitate practice in adult life, so that when the individual is at this stage, already has a history of need for the practice of PA and do it for pleasure or with pleasure and awareness of the need for it.

\section{Physical activity and neurotropic factors}

\section{Concept of neurotropic factor}

According to Camargo et al..$^{13}$ neurotrophic factor is the substance that regulates and maintains the function of the neuron, promoting its growth and survival, and preventing apoptosis. In physiological conditions, neurotrophic factors are involved in the control of neurodevelopment, neural migration, differentiation, neurotransmitter synthesis, synaptic organization and neural plasticity. ${ }^{14}$ However, in pathological conditions changes occur in the neurotransmission system and in the plasticity of the adult, diminishing their capacity to deal with stress situations. ${ }^{14,15}$ Among the several neurotrophic factors we will give special emphasis to brain-derived neurotrophic factor, BDNF (brain-derived neurotrophic factor). BDNF is a protein whose role is of extreme relevance in the development of the central and peripheral nervous system, namely for neuronal development, survival and differentiation. It also exerts influence on brain plasticity, learning and memory. ${ }^{16}$

Relationship between practice of physical activity and neurotropic factors

Physical activity has a great influence on several systems, such as immunity, gastrointestinal and 
nervous systems. In the last one, its benefits have already been demonstrated, as there is improvement in cognitive function, learning and memorization, improvement of cerebral vascularization, neurogenic stimulation and dementia reduction. Physical exercise is very important for the maintenance of quality of life, especially from the age of 50 when several brain alterations occur that can result in the development of neurodegenerative diseases, such as Alzheimer's disease and depression. ${ }^{16}$ Regarding the benefits of PA on the brain, BDNF plays a relevant role. It is important in brain plasticity, learning and memory. This protein is responsible for development, differentiation, regeneration (serotonergic) and neuronal survival. This neurotrophic factor has neuroprotective functions in neurodegenerative diseases or after brain injury and has fundamental factors for homeostasis of neuronal functions. Its increase appears to elicit an antidepressant effect. ${ }^{16,17}$ Studies have shown that physical exercise may contribute to the neurogenesis process and increases BDNF levels in different brain regions, especially in the hippocampus, and that electroconvulsive therapy and antidepressants have the same effect. ${ }^{16,18}$ They also show a relationship between low levels of BDNF and neuropathology's such as schizophrenia, obsessive-compulsive disorder, multiple sclerosis, depression and Alzheimer's disease. ${ }^{16}$ In terms of the relationship of the effects of PA with the neurotrophic effects and specific situations such as memory and depression, respectively, as mentioned earlier, throughout our lives cognitive functions deteriorate, becoming more visible from the age of fifty. This process of aging is physiological and can acquire different intensities and reach different cognitive domains, with memory loss being one of the most common complaints. ${ }^{19}$ The BDNF protein is released by both the brain and muscles, so PA helps regulate the expression of this neurotrophic factor and, consequently, slow down the aging process. ${ }^{20}$ Over time, both animal and human studies of various age groups have been conducted. Since, some studies have shown that the practice of exercise may lead to an increase in cognitive functions, such as memory. Hernandez et al. ${ }^{21}$ implemented a study in the elderly with Alzheimer's that consisted of an PA program (walking, stretching, balance, flexibility) performed twice a week for one hour. At the end of this study, they concluded that the elderly participants of the implemented program had a smaller decline in the activities of daily living and a better performance in walking and balance tasks, comparatively with those who did not participate in this program. This and other studies in elderly people with dementia have been proving that the relation between cognitive functions and functional capacity and PA is beneficial to slow memory loss. ${ }^{21}$ This disease is one of the greatest public health problems in the world due to its high morbidity and mortality. This pathology presents signs and symptoms such as weight loss, feeling guilty, suicidal ideation, hypochondria, complaint of pain and, eventually, psychosis. This contributes to cognitive impairment. The word "depression" comes from the Latin deprimere which means abatement, diminution, sinking. ${ }^{17,} 18$ It reported two different meanings in relation to PA and depression. In one way they point out that there is a decrease in the intensity of depressive symptoms if patients practice physical exercise, especially if the intensity of the exercise is greater. They also refer to a study that points to the fact that elderly people who stop exercising will develop depressive signs and symptoms later. In another way, they point out the influence of depression in PA, where it was found that depressed elderly people are more likely to lead a sedentary life than the elderly who do not present depression. It was also verified, in another study, that sedentarism and age contributed to depression. ${ }^{17}$ From 10 to 14 weeks of supervised exercise can be prescribed, each session lasting between 45 and 60 minutes for the treatment of moderate depression. ${ }^{18}$ Is also reported another study, in which the dependence of the elderly on physical exercise may be related to chronic physical pain, fear of falls and absence of PA. Since when doing stretching exercises, balance, coordination, and strength reveal a decrease in depressive symptoms because of physiological and/or psychological factors. This relationship of activity with decreased depression leads to changes in the immune system. One likely explanation will be the release of hormones such as epinephrine, norepinephrine, somatotropin and cortisol that will act on receptors located 
on lymphocytes and macrophages, providing an increase in the concentration of these cells. The mentioned authors also expose the likelihood that exercise is related to dopamine synthesis (referring to motor performance, locomotor motivation and emotional modulation) because of the increase of calcium values in the brain through the stimulation of the calcium-calmodulin. With all the evidence mentioned above we can conclude that physical activity triggers several physiological processes, such as dopamine synthesis and the release of both neurotrophic factors and hormones. Its consequences are very positive, as it can help prevent various chronic-degenerative diseases (e.g. Alzheimer's disease), psychological illnesses (depression), increasing the quality of life of the individual. ${ }^{22}$

\section{Conclusions}

In the elaboration of this work, we had as main concern to develop a text that, in a simple and objective way, would leave the clear elements about the concept of PA and physical exercise, the benefits of PA, the factors associated with adherence, persistence or abandonment of regular physical activity, as well as to leave informed elements as to the concept of neurotrophic factors and their relation to the practice of PA. With the end of this work, we consider that we have achieved both the general objective, getting to develop our knowledge about PA and neurotrophic factors, as well as the specific objectives in its three domains. We considered achieving the psychomotor goal when performing the first part of this work. We reached the cognitive goal when we explored the relationship between PA practice and neurotrophic factors, especially in the approach to depression and memory. During the production of this work we have come to value more and more the practice of PA and its importance. In this sense, we think we have developed planning and organization skills, analysis of information and critical sense and tolerance to pressure and setbacks. With the realization of this work, we understand that PA is extremely important for the quality of life that everyone has or may have, and it is crucial that health professionals know the benefits of PA so they can intervene by preventing and treating diseases such as depression and Alzheimer's disease.

\section{References}

1. Vasconcelos M. Níveis de Actividade Física e Prática Desportiva de Crianças e Jovens dos Dois Sexos dos 10 aos 19 anos de idade. Thesis. Porto, Portugal: Universidade do Porto; 2001.

2. Mendes R. Prática de Exercício Físico e Níveis de Atividade Física Habitual em Doentes com Diabetes Tipo 2 Estudo Piloto em Portugal. Thesis. Covilhã, Portugal: Universidade da Beira Interior; 2013.

3. WHO Global recommendations on physical activity for health; [Internet] 2016. Available from: http://www.who.int/ dietphysicalactivity/factsheet_recommendations/en/ [cited 2018, Jul 16].

4. Bounds G. Physical Activity and Health: A Report of the Surgeon General. Atlanta: Centers for Disease Control and Prevention; 2006

5. Moreira $\mathrm{S}$. As actividades lúdico-desportivas nas práticas de lazer em crianças do $1^{\circ}$ ciclo. Thesis. Minho, Portugal: Universidade do Minho; 2006.

6. Medeiros J. Atividade física e exercício físico e os efeitos profiláticos nas doenças cardiovasculares. EF Deportes 2010;15:148-60.

7. Flores D. Atividade Física: seus benefícios para prevenção de doenças cronicas degenerativas. Thesis. São José, Canoas, Brazil: Universidade Luterana do Brasil; 2009.

8. Lazzoli J, Nóbrega A, Carvalho T, Oliveira M, Teixeira J, Leitão $\mathrm{M}$, et al. Atividade física e saúde na infância e adolescência. Rev Bras Med Esporte 1999;4:107-9.

9. Matsudo S, Matsudo V. Prescriçäo e benefícios da atividade física na terceira idade. Revista Brasileira de Ciência \& Movimento 1992;6:19-30.

10. Silva RS, da Silva I, da Silva RA, Souza L, Tomasi E. Physical activity and quality of life. Cien Saude Colet 2010;15:115-20. Portuguese.

11. Costa B, Bottcher L, Kokubun E. Aderência a um programa de atividade física e fatores associados. Motriz 2009; 15:25-36.

12. Santos $S$, Nijnik J. Motivos de adesão à prática de atividade física na vida adulta intermediária I. Revista Mackenzie de Educação Física e Esporte 2006;5:23-34.

13. Camargo E, Silva V. Mecanismo envolvidos na regeneração de lesões nervosas periféricas. Revista Saúde e Pesquisa 2010;3:93-8.

14. Grillo R. Fator neurotrófico derivado do cérebro e esquizofrenia. Thesis. Porto Alegre, Brazil: Universidade federal do Rio Grande Do Sul; 2005.

15. Iritani S, Niizato K, Nawa H, Ikeda K, Emson PC. Immunohistochemical study of brain-derived neurotrophic factor and its receptor, TrkB, in the hippocampal formation of schizophrenic brains. Prog Neuropsychopharmacol Biol Psychiatry $2003 ; 27: 801-7$.

16. Vancini R, Lira C, Arida R. Efeito da atividade física sobre a aptidão cerebral. Centro de Estudos de Fisiologia do Exercício; 2008

17. Reis J. Atividade Física: um complemento a considerar no tratamento da depressão. Thesis. Covilhã, Brazil: Universidade da Beira Interior; 2012. 
18. Moraes H, Deslandes A, Ferreira C, Pompeu F, Ribeiro $\mathrm{P}$, Laks J. O exercício físico no tratamento da depressão em idosos: revisão sistemática. Rev Psiquiatr Rio Gd Sul 2006;29:70-9.

19. Chiari H, Mello M, Rezeak P, Antunes H. Exercício físico, atividade física e os benefícios sobre a memória de idosos. Rev Psicol Saúde 2010;2:42-9.

20. Gonçalves MP, Tomaz C, Sangoi C. Considerações sobre envelhecime nto, memória e atividade física. Revista Brasileira de Ciência e Movimento 2009;14:101-8.
21. Hernandez S, Coelho F, Obbi S, Stella F. Efeitos de um programa de atividade física nas funções cognitivas, equilíbrio e risco de quedas em idosos com demência de Alzheimer, exercício físico e função cognitiva. Braz J Phys Ther 2010;14:68-74

22. Campos M. O exercício físico e sua relação com o fator neurotrófico derivado do cérebro (BDNF) e a plasticidade sináptica: uma revisão bibliográfica. Thesis. Porto Alegre, Brazil: Universidade Federal do Rio Grande do Sul; 2014.

Conflicts of interest.-The authors certify that there is no conflict of interest with any financial organization regarding the material discussed in the manuscript.

Manuscript accepted: May 17, 2018. - Manuscript received: April 18, 2018. 